\title{
Use of Physical and Intellectual Activities and Socialization in the Management of Cognitive Decline of Aging and in Dementia: A Review
}

\author{
Myuri Ruthirakuhan, Angela C. Luedke, Angela Tam, Ankita Goel, \\ Ayaz Kurji, and Angeles Garcia \\ Department of Medicine (Geriatrics) and Centre for Neuroscience, Queen's University, Kingston, ON, Canada K7L 5A2 \\ Correspondence should be addressed to Angeles Garcia, garciaa@providencecare.ca
}

Received 7 July 2012; Accepted 31 October 2012

Academic Editor: Richard F. Gillum

Copyright (C) 2012 Myuri Ruthirakuhan et al. This is an open access article distributed under the Creative Commons Attribution License, which permits unrestricted use, distribution, and reproduction in any medium, provided the original work is properly cited.

\begin{abstract}
Lifestyle nonpharmacological interventions can have a deep effect on cognitive aging. We have reviewed the available literature on the effectiveness of physical activity, intellectual stimulation, and socialization on the incidence of dementia and on the course of dementia itself. Even though physical activity appears to be beneficial in both delaying dementia onset and in the course of the disease, more research is needed before intellectual stimulation and socialization can be considered as treatments and prevention of the disease. Through our paper, we found that all three nonpharmacological treatments provide benefits to cognition and overall well-being in patients with age-related cognitive impairments. These interventions may be beneficial in the management of dementia.
\end{abstract}

\section{Introduction}

Alzheimer's disease $(\mathrm{AD})$ is a neurodegenerative disorder with devastating consequences [1]. Despite being the most common cause of dementia, affecting approximately 5.4 million Americans [2] and almost $50 \%$ of people over the age 85 [3], no cure has yet been discovered. Efforts are also focusing on the development of more effective strategies to slow the progression of $\mathrm{AD}$ to increase the quality of life of those affected. Even a two-year delay in disease onset would reduce the prevalence of $\mathrm{AD}$ among Americans by two million people within fifty years [4]. If an intervention that delayed the onset of $\mathrm{AD}$ by five years had been applied back in 1997, we would have seen a 50\% reduction in $\mathrm{AD}$ incidence [4]. Research on strategies to slow the development and progression of $\mathrm{AD}$ is arguably more important now than ever before, since the number of people with $\mathrm{AD}$ is expected to nearly triple over the next forty years [4], and dementia is the most important contributor to disability in the elderly [5].
Among others, three nonpharmacological interventions are particularly relevant as they might positively influence cognition, general functioning, and overall quality of life. These three strategies are physical exercise, intellectual stimulation, and social interaction. While there are studies that evaluate the role of individual and multimodal interventions on $\mathrm{AD}$, there is a lack of literature on the combination of all three. The purpose of this paper is to review key areas of the literature that focus on the effects of physical exercise, intellectual stimulation, and socialization strategies on $\mathrm{AD}$ evolution, as they collectively play an important role in the management of Alzheimer's disease. Physical exercise encapsulates both aerobic exercises (e.g., walking and cycling) and nonaerobic exercises (e.g., strength and resistance training; flexibility and balance exercises). For intellectual stimulation, we examine studies that have evaluated the prognostic effects of either cognitive hobbies (e.g., reading, word puzzles, and card games) or cognitive training (e.g., computer training games/paradigms that target specific cognitive domains such as memory and attention). Social interaction is defined as 
the participation of an $\mathrm{AD}$ patient in group-related activities, such as mealtime conversations, support groups, or other forms of social engagement.

Evidence-based nonpharmacological interventions are an essential part of any management plan, especially for geriatric populations in whom the harmful effects of polypharmacy are a major concern. Nonpharmacological strategies are sometimes even more effective than pharmacological interventions and are empowering to proactive individuals who seek to gain greater personal control over their mental and physical health. We suggest that comprehensive $\mathrm{AD}$ management plans should include evidence-based nonpharmacological strategies.

\section{Methods}

Electronic databases (PubMed, Web of Science, and MEDLINE) were searched for the period from 1980 to 2012 with the combination of key words: $\mathrm{AD}$, dementia, incident $\mathrm{AD}$, aging, cognition, cognitive aging, exercise, aerobic exercise, resistance training, cognitive reserve, intellectual stimulation, cognitive stimulation, hobbies, cognitive training, memory training, brain games, leisure activities, socialization, loneliness, social network, support groups, quality of life, activities of daily living, nonpharmacological, and treatment. We included studies that examined the preservation of cognition in $\mathrm{AD}$ populations and $\mathrm{AD}$ incidence.

\section{Physical Activity}

The health benefits attributed to physical activity are numerous and well known. Exercise has been associated with a lower incidence in many chronic diseases, such as coronary heart disease [6], type 2 diabetes [7], obesity [8], cancer [9], bone loss [10], and high blood pressure [11]. We have reviewed the effects of physical exercise on cognition.

Higher cardiorespiratory fitness has been related to higher scores on tests of cognitive function [12]. A metaanalysis of randomized controlled trials examining the relationship between exercise and cognition showed modest improvements in attention, processing speed, executive function, and memory among older adults in the treatment arms [13]. This is highly relevant for the elderly population, as it suggests that physical activity can serve as a preventative measure against age-related cognitive decline [14].

Several large longitudinal studies followed older adults without cognitive impairments at baseline and measured rate of incident dementia to clarify the relationship between physical activity and incident cognitive loss. A large prospective study by Podewils et al. identified an inverse relationship between physical activity and dementia risk [15]. Compared to no exercise, physical activity has been linked with reduced risks of developing cognitive impairment and dementia [16] with the risk for dementia being further reduced with increasing levels of physical activity. Larson and colleagues found that persons who exercised three or more times per week had a reduced risk of developing dementia compared to those who exercised less, and the reduction was more marked among those with the poorest physical function at baseline [17]. These results were corroborated by Buchman et al. who found that participants in the lowest percentiles of physical activity had more than twice the risk of developing dementia than those in the highest percentiles of physical activity [18]. Furthermore, Lautenschlager et al. demonstrated that these results might be transferable to adults with mild cognitive impairment (MCI), and, thus, at high risk for dementia; participants who underwent exercise training showed modest improvements in cognition after six months [19]. Physical exercise has, therefore, been recommended as a preventative measure of mild cognitive impairment and dementia $[20,21]$.

There is much less research focusing on the effect of physical activity in $\mathrm{AD}$ patients. This may be due to the challenges of implementing an exercise regime while managing the behavioral and emotional disturbances in $\mathrm{AD}$ patients, particularly in the later stages of the disease. However, the results in the available literature are promising. Early research involving $\mathrm{AD}$ patients in nonrandomized controlled trials showed significant cognitive improvements among participants who underwent cycling training and somatic and isotonic-relaxation exercises [22, 23].

Physical exercise may have beneficial effects in $\mathrm{AD}$ patients beyond cognition as well. A meta-analysis on 30 randomized controlled trials that employed exercise, behavioral and environmental manipulations in patients with cognitive impairment found exercise had positive effects on strength and cardiovascular fitness in addition to improvements in behavior and cognition [24-26]. Further evidence supporting multifaceted positive effects of exercise on $\mathrm{AD}$ can be traced to recent randomized controlled trials of physical exercise regimes on $\mathrm{AD}$ patients (Table 1).

Compared to controls, patients in the intervention programs showed better physical functioning (functional reach, walking, and mobility). After treatment, these patients also showed improved performance of activities of daily living (ADLs), and less cognitive decline and cognitive improvement in some cases. Physical exercise, therefore, appears to be beneficial for AD patients. While the majority of the studies did not find any differences in depression, one study by Steinberg found increased depression and decreased quality of life in patients who underwent the exercise intervention [31]. Further research into the effect of physical exercise on mood and quality of life in $\mathrm{AD}$ patients is, therefore, required.

When considering the role of exercise on $\mathrm{AD}$, it is important to note that any positive results may be due to a placebo effect, even in randomized controlled trials. However, due to the varied nature of the outcome measures used in these studies, it is unlikely that every intervention group demonstrated significant gains over the controls due to a placebo effect alone. Furthermore, control group members never appeared to show any improvement and often showed higher rates of functional and cognitive decline.

The majority of the reviewed studies employed aerobic exercise as a component to their therapy. Yet, two studies demonstrated that nonaerobic activity, such as strength and flexibility training, might also be beneficial to $\mathrm{AD}$ patients 
TABLE 1: Summary of randomized controlled trials of physical exercise regimes in AD patients.

\begin{tabular}{|c|c|c|c|c|c|c|}
\hline Study & $\begin{array}{l}\text { Length and } \\
\text { frequency }\end{array}$ & Type of exercise & Sample & $\begin{array}{l}\text { MMSE } \\
\text { (baseline mean) }\end{array}$ & Outcome measures & Major findings \\
\hline Kemoun et al. [27] & $\begin{array}{l}15 \text { wks; } 1 \mathrm{~h} \\
\text { sessions 3x/wk }\end{array}$ & $\begin{array}{l}\text { Aerobic, } \\
\text { balance, and } \\
\text { endurance }\end{array}$ & $\begin{array}{l}n_{\mathrm{ex}}=16 \\
n_{c}=15\end{array}$ & 12.6 & $\begin{array}{l}\text { Walking speed, stride } \\
\text { length, double limb } \\
\text { support time, and ERFC }\end{array}$ & $\begin{array}{l}\text { Higher ERFC and } \\
\text { walking parameter } \\
\text { scores in exercise group; } \\
\text { positive correlation } \\
\text { between walking } \\
\text { parameters and ERFC } \\
\text { scores }\end{array}$ \\
\hline Miu et al. [28] & $\begin{array}{l}3 \text { mos; } \sim 1 \mathrm{~h} \\
\text { sessions } 2 \mathrm{x} / \mathrm{wk}\end{array}$ & $\begin{array}{l}\text { Aerobic, } \\
\text { flexibility }\end{array}$ & $\begin{array}{l}n_{\mathrm{ex}}=36 \\
n_{c}=49\end{array}$ & 20 (median) & $\begin{array}{l}\text { SF-12, } 6 \text { min walk, } \\
\text { functional reach, BBS, } \\
\text { MMSE, ADAS-Cog, and } \\
\text { CSDD }\end{array}$ & $\begin{array}{l}\text { Improvement in walking } \\
\text { and functional reach in } \\
\text { exercise group }\end{array}$ \\
\hline Roach et al. [29] & $\begin{array}{l}16 \text { wks; } \\
15-30 \mathrm{~min} \\
\text { sessions } 5 \mathrm{x} / \mathrm{wk}\end{array}$ & $\begin{array}{l}\text { Strength, } \\
\text { flexibility, } \\
\text { endurance, and } \\
\text { balance }\end{array}$ & $\begin{array}{l}n_{\mathrm{ex}}=28 \\
n_{\mathrm{soc}}=25 \\
n_{\text {walk }}=29\end{array}$ & 10.7 & $\begin{array}{l}\text { ACIF, } 6 \text { min walk, and } \\
\text { MMSE }\end{array}$ & $\begin{array}{l}\text { Improved transfer in } \\
\text { exercise group }\end{array}$ \\
\hline Rolland et al. [30] & $\begin{array}{l}1 \mathrm{yr} ; 1 \text { h session } \\
2 \mathrm{x} / \mathrm{wk}\end{array}$ & $\begin{array}{l}\text { Aerobic, } \\
\text { strength, } \\
\text { flexibility, and } \\
\text { balance }\end{array}$ & $\begin{array}{l}n_{\mathrm{ex}}=67 \\
n_{c}=67\end{array}$ & 8.8 & $\begin{array}{l}\text { Katz Index of ADLs, } \\
\text { walking speed, } \\
\text { get-up-and-go, one-leg } \\
\text { balance, MNA, NPI, and } \\
\text { MADRS }\end{array}$ & $\begin{array}{l}\text { Less decline in overall } \\
\text { ADLs in exercise group }\end{array}$ \\
\hline Steinberg et al. [31] & $12 \mathrm{wks} ; \sim 3 \mathrm{x} / \mathrm{wk}$ & $\begin{array}{l}\text { Aerobic, } \\
\text { strength, } \\
\text { balance, and } \\
\text { flexibility }\end{array}$ & $\begin{array}{l}n_{\mathrm{ex}}=14 \\
n_{c}=13\end{array}$ & 20.1 & $\begin{array}{l}\text { YPAS, 8-ft walk, JTT, } \\
\text { sit-to-stand, MMSE, } \\
\text { BNT, HVLT, ADQRL, } \\
\text { NPI, CSDD, and SCB }\end{array}$ & $\begin{array}{l}\text { Improved performance } \\
\text { in JTT and sit-to-stand, } \\
\text { increased depression, } \\
\text { and decreased ADQRL } \\
\text { in exercise group }\end{array}$ \\
\hline Venturelli et al. [32] & $\begin{array}{l}24 \mathrm{wks} ; 30 \mathrm{~min} \\
\text { sessions } 4 \mathrm{x} / \mathrm{wk}\end{array}$ & $\begin{array}{l}\text { Mobility, } \\
\text { aerobic }\end{array}$ & $\begin{array}{l}n_{\mathrm{ex}}=12 \\
n_{c}=12\end{array}$ & 13 & $\begin{array}{l}6 \text { min walk, Barthel } \\
\text { Index of ADLs, and } \\
\text { MMSE }\end{array}$ & $\begin{array}{l}\text { Improvements in } \\
\text { walking and ADLs, } \\
\text { slower decline in MMSE } \\
\text { in exercise group }\end{array}$ \\
\hline $\begin{array}{l}\text { Vreugdenhil et al. } \\
\text { [33] }\end{array}$ & $\begin{array}{l}4 \text { mos; >30 mins } \\
\text { daily }\end{array}$ & $\begin{array}{l}\text { Strength, } \\
\text { balance, and } \\
\text { aerobic }\end{array}$ & $\begin{array}{l}n_{\mathrm{ex}}=20 \\
n_{c}=20\end{array}$ & 22.9 & $\begin{array}{l}\text { ADAS-Cog, MMSE, } \\
\text { functional reach, Timed } \\
\text { Up and Go, sit-to-stand, } \\
\text { Barthel Index of ADLs, } \\
\text { GDS, CIBIC-plus, and } \\
\text { Zarit Burden Interview }\end{array}$ & $\begin{array}{l}\text { Improved scores on } \\
\text { ADAS-Cog, MMSE, } \\
\text { CIBIC-plus, functional } \\
\text { reach, Timed Up and } \\
\text { Go, sit-to-stand, and } \\
\text { ADLs in exercise group } \\
\end{array}$ \\
\hline $\begin{array}{l}\text { Yàgüez et } \\
\text { al. [34] }\end{array}$ & $\begin{array}{l}6 \text { wks; } 1.5 \mathrm{~h} \\
\text { sessions } 1 \mathrm{x} / \mathrm{wk}\end{array}$ & $\begin{array}{l}\text { Flexibility, } \\
\text { eye-hand } \\
\text { coordination }\end{array}$ & $\begin{array}{l}n_{\mathrm{ex}}=15 \\
n_{c}=12\end{array}$ & 22.1 & CANTAB-Expedio & $\begin{array}{l}\text { Improvements in } \\
\text { attention, visual } \\
\text { memory recognition, } \\
\text { and working memory in } \\
\text { exercise group }\end{array}$ \\
\hline
\end{tabular}

$n_{\mathrm{ex}}, n_{\mathcal{c}}, n_{\mathrm{soc}}, n_{\mathrm{walk}}$ : number of participants in exercise program, control group, social conversation group, and walking group, respectively. ACIF: Acute Care Index of Function, ADAS-Cog: Alzheimer's Disease Assessment Scale-Cognitive Subscale, ADL: activities of daily living, ADQRL: Alzheimer's Disease Quality Related Life Scale, BBS: Berg Balance Scale, BNT: Boston Naming Test, CANTAB-Expedio: The Cambridge Neuropsychological Test Automated Battery, CIBIC-plus: Clinician's Interview-Based Impression of Change Plus Caregiver Input, CSDD: Cornell Scale for Depression in Dementia, ERFC: Rapid Evaluation of Cognitive Function, GDS: Geriatric Depression dcale, HDS: Hamilton Depression Scale, HVLT: Hopkins Verbal Learning Test, JTT: Jebsen Total Time, MADRS: Montgomery-Asberg Depression Rating Scale, MMSE: Mini-Mental State Examination, MNA: Mini-Nutritional Assessment, NPI: Neuropsychiatric Inventory, SCB: Screen for Caregiver Burden, SF-12: SF-12 Quality of Life Questionnaire, SF-36: Short-Form Health Survey, SIP: Sickness Impact Profile, and YPAS: Yale Physical Activity Survey.

$[29,34]$. Studies involving cognitively normal adults and nonaerobic exercises offer insight into the potential effects of nonaerobic activity and cognitive decline. Cassilhas et al. found that participants who underwent resistance training showed significant improvements in memory measures compared to controls [35]. Liu-Ambrose and colleagues, who used a combination of resistance and balance exercises as their intervention, saw significant improvements in response inhibition in their intervention group while the control group deteriorated [36]. Resistance training may, therefore, provide protective effects for cognition. The effect of stretch exercises, such as yoga, on cognition has been briefly examined; Oken and colleagues found no cognitive differences between their control and yoga groups after treatment [37]. However, more research into stretch exercises and cognition is required to draw more definitive conclusions. 
Future studies may investigate which types of exercises, or combinations of exercises, yield the greatest benefit specifically to $\mathrm{AD}$ patients. It is important to mention that some of the aforementioned randomized controlled trials $[27,29,30,32]$ were conducted on participants recruited from long-term care facilities, and thus were likely to be in the more moderate-advanced stages of the disease. These studies demonstrate not only the feasibility of the exercise programs in $\mathrm{AD}$ patients but also that patients can benefit greatly from physical exercise even in moderate-to-severe stages of the disease.

Enhanced neuroplasticity might be underlying the improvements seen. Colcombe and colleagues demonstrated that older adults without dementia who performed aerobic exercises had greater grey and white matter volumes compared to adults who engaged in stretching and toning exercises [38]. Exercise has also been associated with functional connectivity between brain networks often affected by age, such as the default mode, frontal parietal, and frontal executive networks, in older adults without dementia [39]. While randomized controlled trials in $\mathrm{AD}$ patients examining the relationship between neuroplasticity and exercise are underway, correlational studies examining brain volumes and cardiorespiratory fitness have been done. In AD patients, cardiorespiratory fitness has been associated with brain volume. $\mathrm{VO}_{2}{ }^{\text {peak }}$, peak oxygen consumption, has been positively correlated with greater whole brain volume and white matter volume [40], notably in the inferior parietal lobule, hippocampal, and parahippocampal regions [41]. Future results of randomized controlled trials will improve our knowledge in this field of research.

Overall, physical activity offers promising outcomes for cognition and physical health in the elderly population and AD patients.

\section{Intellectual Activity}

Engagement in intellectually stimulating activities has been linked with reduced risk of developing $\mathrm{AD}$ and intellectual stimulation has been widely explored as a nonpharmacological treatment option for dementia [42].

Among cognitively normal older persons, randomized control trials employing intellectual training concluded that cognitive interventions produce protective and potentially long lasting positive effects in various cognitive domains as well as activities of daily living [43]. There is also evidence that frequent engagement in hobbies, including reading, puzzles, and games, for at least six hours per week reduces the risk of incident dementia [44]. The concept of intellectual stimulation as a preventative measure for dementia in healthy older adults can be parallel to the notion of building a "compensatory mechanism" or "cognitive reserve" [45-48].

Cognitive reserve refers to the hypothesis that individual differences shaped by inherent characteristics and external sources including intelligence, years of education, occupation, and intellectual activities, may provide neural protective support against dementia [45-47]. It has been argued that these collective life experiences may contribute to building cognitive reserve and, thus, provide skills to compensate for AD pathology [45-47]. In other words, a greater cognitive reserve might delay the appearance of dementia despite the presence of neuropathology, after which a rapid progression of cognitive decline may ensue once pathology is significant enough to result in $\mathrm{AD}$ diagnosis. Thus, AD patients with higher education and occupation accomplishments suffer more rapid decline in cognitive abilities when compared to $\mathrm{AD}$ patients with less education and occupational attainment following diagnosis [49]. Another study by Helzner and colleagues [50] investigated the relationship between premorbid leisure activity and rate of cognitive decline in $\mathrm{AD}$ patients. Leisure activities were classified into four categories: intellectual, social, physical, and other. Higherfrequency participation in intellectual leisure activities prior to $\mathrm{AD}$ diagnosis was associated with delayed $\mathrm{AD}$ onset followed by faster cognitive decline. The study by Helzner and colleagues [50] provides evidence for the benefits of intellectual stimulation on slowing down $\mathrm{AD}$ development.

Besides reducing the risk of dementia, cognitive interventions later in life may affect functional decline in $\mathrm{AD}$. Treiber and colleagues [51] explored the association between engaging in cognitively stimulating activities in late life and the rate of cognitive decline in incident $\mathrm{AD}$. This study included a wide range of intellectual activities that required varying levels of cognitive demand, for example, completing puzzles, reading, watching television, listening to music, and cooking. The results suggested that higher-frequency participation in stimulating activities in early stages of dementia resulted in slower cognitive decline. However, as time progressed there was an overall decrease in participation in activities, which might reflect the nature of AD in terms of functional abilities.

Intellectual stimulation can be divided into several categories including cognitive stimulation, cognitive training, and cognitive rehabilitation (Table 2) [48, 52-54]. Each type of stimulation targets various cognitive domains including memory and attention, or even more generally, activities of daily living [55]. The focus of this paper is to investigate the literature on the link between intellectual stimulation and rate of cognitive decline in patients with dementia.

\subsection{Cognitive Stimulation and Reality Orientation in Demen-} tia. Cognitive stimulation therapy (CS) encompasses a variety of mentally stimulating activities and is less formal than other forms of cognitive training [53]. In addition, cognitive stimulation can be passive, such as listening to music, or active, such as playing a game [53]. The goal of CS is to enhance a wide range of functioning, including social skills, often through group discussions [48, 56]. An earlier randomized control trial included a total of 167 participants (97 in the treatment group and 70 in the control group). This study examined the relationship between CS, cognitive functioning, and quality of life [57]. The CS group participated in activities including crafts, games, and singing compared to a control group who received no intervention. The sessions ran for seven weeks and consisted of a total of 14 sessions, one 45-minute session twice a 


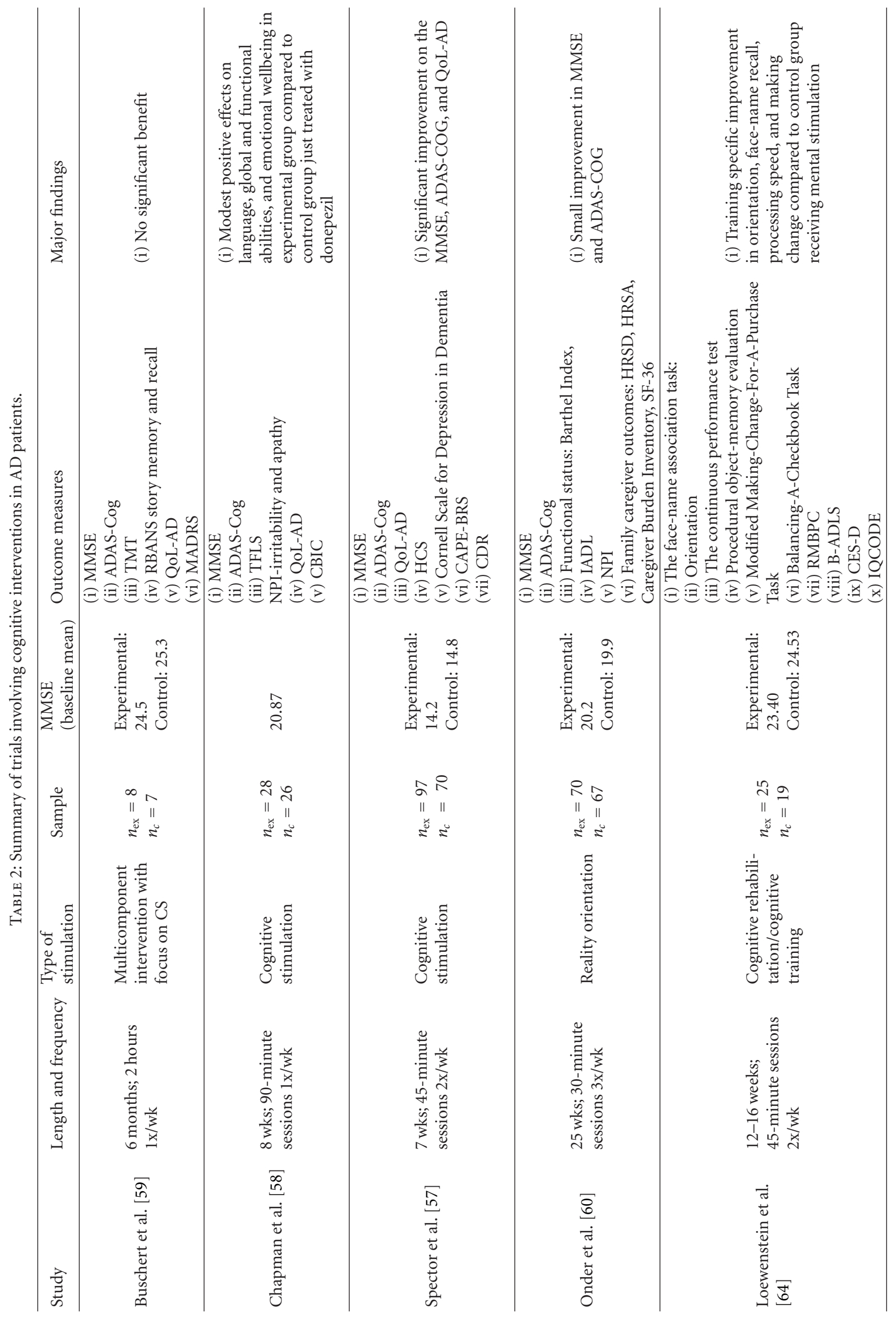




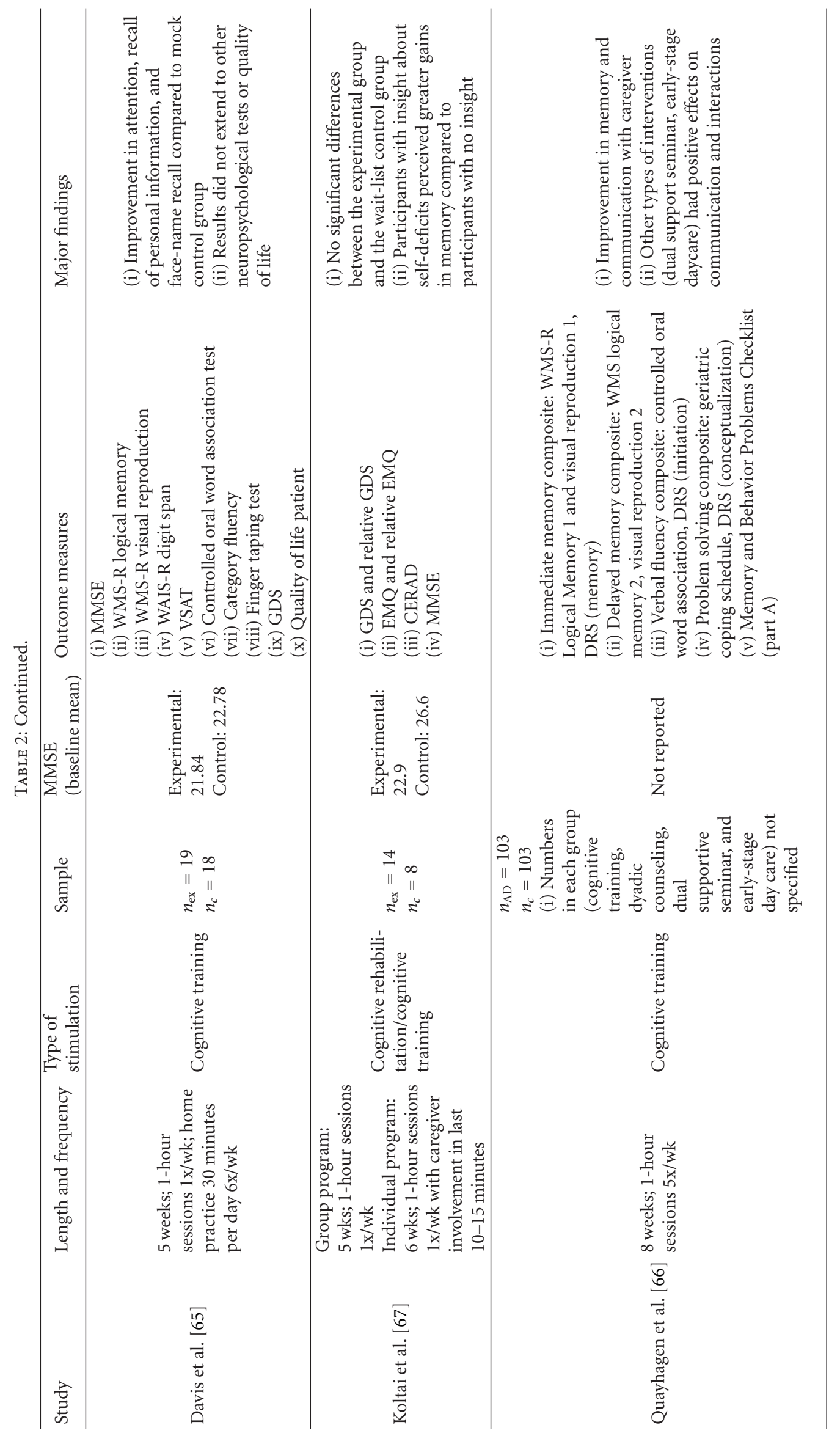




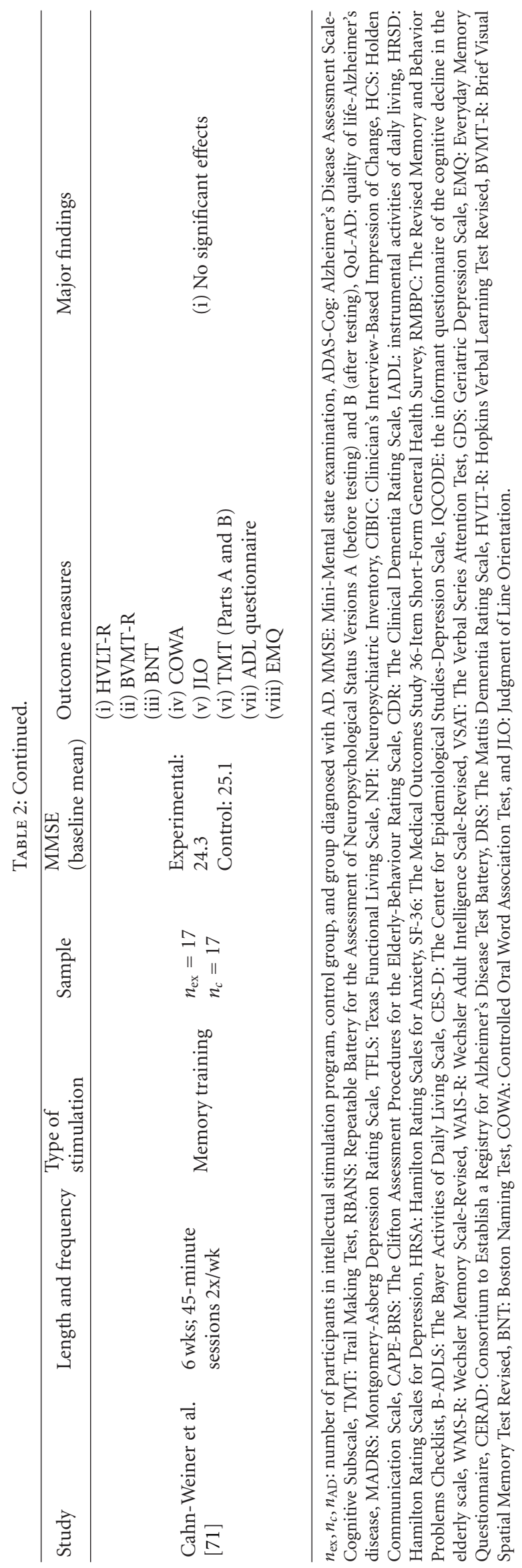


week. Assessment measures included cognitive tests and measures of quality of life, communication, behavior, global functioning, depression, and anxiety. The results indicated positive effects of CS on cognitive functioning as well as ADLs. Other studies found CS to be beneficial on measures of language [58], emotional wellbeing [58], and cognitive tests [57]. Unfortunately, not all studies found significant benefits of CS on dementia patients [59].

Reality orientation (RO) is a component of CS and focuses on orienting the individual with $\mathrm{AD}$ to person, place and time $[52,56]$. Studies on RO in dementia indicate slight advantages on cognitive tests $[60,61]$. A recent Cochrane review of fifteen randomized control trials investigated the effectiveness of RO and some CS in AD [56]. The review included 718 participants, with 407 participants in the treatment group and 311 in the control group. Intervention length varied between four weeks and 24 months, with sessions ranging from 30 to 90 minutes. Overall cognitive functioning was improved in $\mathrm{AD}$ patients receiving $\mathrm{RO}$ and CS, with some studies indicating additional positive changes to social and communicative functioning and quality of life [56].

Based on the current literature on the efficacy of CS and $\mathrm{RO}$ on decline in $\mathrm{AD}$, it appears that both forms of intervention may provide encouraging results for slowing decline and improving quality of life $[52,56]$.

4.2. Cognitive Training and Cognitive Rehabilitation in Dementia. Cognitive training (CT) targets individual or multiple cognitive domains through teaching specific skills. It aims to improve functioning in the targeted area as well as the possibility of extending the improvements to more general functioning and other cognitive domains [54, 62]. Similarly, cognitive rehabilitation (CR) aims at improving daily functioning by identifying individualized strengths and weaknesses $[56,63]$. Due to the significant amount of overlap between CT and CR, both interventions are sometimes combined [62].

Several reviews on CT suggest mixed outcomes in terms of effectiveness as a treatment option for $\mathrm{AD}[52,62]$. While several studies show improvement in specific cognitive domains targeted by training [64-66], others fail to report any significant changes [67] or extend results to more general functioning [65]. A Cochrane review by Clare and Woods [62] concluded that CT and CR provided no positive or negative effects on cognitive performance in $\mathrm{AD}$ compared to control groups. Conversely, Small and colleagues [68] found CT to have a negative impact on mood in patients with dementia and in their caregivers. A meta-analysis showed that CT had modest positive effects on various aspects of cognition, including learning, memory, executive and general functioning, and depression [55]. A randomized control trial using CR alone found that goal performance and satisfaction was improved compared to the control groups receiving relaxation therapy [63].

Another review investigated the literature on CT in preventing incident $\mathrm{AD}$, preventing $\mathrm{MCI}$ conversion to $\mathrm{AD}$, and slowing $\mathrm{AD}$ progression $[48,69]$. The results suggested that CT may be most beneficial to healthy elderly and at risk individuals with MCI as opposed to AD treatment [48].

There is a lack of a consensus in the literature as to whether $\mathrm{CT}$ can ameliorate symptoms of $\mathrm{AD}[52,62]$. Although some studies show promising results for CT [55], others reveal improvement only in specific areas of cognitive training, such as learning personal information and aspects of attention [65]. CR, on the other hand, might produce more general benefits to cognitive functioning [63].

4.3. Specific Cognitive Domain Training in Dementia. Targets of intellectual stimulation can also be divided into unidomain and multidomain. While most cognitive interventions target multidomain areas of cognition and functioning, some are specific to memory training. Although some studies suggest memory rehabilitation can improve specific memory function with sufficient time and caregiver involvement [70], a randomized control study focusing on mnemonic memorization strategies found no significant difference between the treatment and control groups [71].

4.4. Comparing Interventions. Ballard and colleagues recently reviewed $\mathrm{CT}, \mathrm{CS}, \mathrm{CR}$, and memory aids and concluded that all forms of intervention may offer modest effects, with most benefit attributed to CS [52]. In comparing CT and CS, both resulted in improvement of activities of daily living; however, only CS resulted in improvement in behavior $[53,72]$. There are several reasons to explain differences in effectiveness of treatment types. There can be a significant overlap between types of intellectual stimulation, making it difficult to identify which types of interventions are most effective. The fact that some studies implementing only memory training were included in reviews of cognitive training [55] might also contribute to mixed findings in reviews of CT and cloud the effectiveness of each type of treatment. Moreover, differences in the past history and disease stages of the patients might also explain different results. Diversity in methodologies, such as sample size, variations in inclusion criteria, inconsistent outcome measures and protocols, also renders between study comparisons problematic [55]. In addition, not all studies control for medications such as cholinesterase inhibitors, which might contribute to positive effects along with stimulating activities [53].

Nonetheless, intellectual stimulation is a promising tool for slowing the progression of AD. More randomized control trials that compare generalizability of training programs, long-term effects, and rate of cognitive decline across different intervention types are needed to assess the most effective form of intellectual stimulation.

\section{Socialization}

AD patients' feelings of incompetence, along with societal misconceptions, may accelerate the progression of AD [73]. So far, the relevance of the social environment surrounding an individual with $\mathrm{AD}$ has been mostly overlooked, but the results of increased social engagement on risk of dementia 
open the opportunity to incorporate socialization therapies in $\mathrm{AD}$.

\subsection{Influence of Increased Socialization on Incident Dementia.} The cognitive reserve hypothesis, as previously described [45-47], includes social engagement as an important skill set for delaying the development of AD. An increase in social engagement with the surrounding environment can be correlated with angiogenesis, synaptogenesis, and neurogenesis [74]. Fratiglioni et al. also explained the relevance of stress reduction in cognition through the stress hypothesis [74] and increased social engagement is associated with improved selfesteem [73]. The importance of social engagement in reducing the risk of $\mathrm{AD}$ can be further supported by the vascular hypothesis. It is important to note that vascular risk factors, which could be reduced with increased social engagement, can contribute to the pathogenesis and progression of $\mathrm{AD}$ $[74,75]$.

Table 3 showcases the importance of social engagement on the prevention of $\mathrm{AD}$, there is a lack of research on the effects of social engagement on $\mathrm{AD}$ prognosis. Collaborative research in the fields of sociology, psychology, neuroscience, and medicine will be important in this area.

\subsection{Influence of Socialization on AD Population. Many AD} patients sense that their cognitive impairment isolates them from other people leading to anxiety, depression, societal withdrawal, and decreased self-confidence. Manipulating the social environment around $\mathrm{AD}$ patients may help them regain a sense of self-worth and a better attitude towards life. This may improve eating and exercise habits and social interactions, which may result in improved $\mathrm{AD}$ prognosis [73].

Shaping how cognitively normal individuals relate to $\mathrm{AD}$ patients can play an important role in improving patients' social environment and interactions [73]. It is extremely important that surrounding healthy individuals (friends, family members, etc.) maintain a supportive atmosphere towards $\mathrm{AD}$ patients to ensure that, regardless of their cognitive abilities, they have a place in society and that their identity is valued. After multiple experiences, MacRae [73] reported that married $\mathrm{AD}$ patients whose spouses encouraged them to live life as normally as possible, and to remain socially engaged, preserved a "positive sense of self while living with dementia." This led to healthier eating habits and increased physical exercise and participation in cognitively and socially stimulating activities, thereby improving quality of life [73].

In further support of how a positive social atmosphere can benefit individuals with AD, Keller et al. [81] analyzed how shared mealtimes can enhance social engagement. With disease progression, alterations must be made to accommodate for changes in eating conduct (difficulties with using utensils or wandering), swallowing ability, and the ability to prepare food safely. Therefore, an event that was once a traditional social occasion may become an event filled with tension, frustration, and disappointment. As a result, the social experience associated with mealtimes may become limited and possibly nonexistent. However, reports show that $\mathrm{AD}$ patients benefit from shared mealtimes by getting motivated through another's physical presence to improve their attentional, planning, and decision making abilities [81].

Loneliness is widely reported by patients with dementia, arising from the feeling of not having anyone to relate to, dissatisfaction with one's way of living, and social isolation. Recent studies have attempted to reduce this sense of "loneliness" and assess its effects on cognition [76]. Pitkala et al. [75] examined the effects of enhancing social stimulation on cognitive outcomes in the elderly and patients with mild dementia. Volunteers were divided into three social intervention groups, according to their preference: (1) art, inspiring activities, and discussions, (2) exercise and discussions, and (3) therapeutic writing and discussions. Within each group, they were further divided into intervention or placebo. Participants in the intervention groups improved significantly over the course of 3 months on the Alzheimer's Disease Assessment Scale (ADAS-Cog) compared to control groups. Furthermore, a health-related quality of life (HRQol) questionnaire conducted at baseline and at 12 months revealed significant improvements in quality of life in the social intervention groups [75].

Support groups are another intervention aimed to assist with the psychosocial difficulties that patients diagnosed with early-stage dementia face [82]. A clinical trial compared quality of life (QOL), depression, and family communication outcomes between an early-stage memory loss (ESML) support group and a wait-list (WL) control group [83]. The ESML condition involved 90-minute weekly sessions for 9 weeks. The WL condition did not participate in the social support groups, but received educational material from their local Alzheimer's Association group and were encouraged to contact relevant support services should any questions or concerns arise. Results showed that in comparison to control participants, ESML participants expressed better QOL and less depressive symptoms after 9 weeks. Furthermore, the improved QOL among ESML participants was associated with an improvement of cognition and family communication [83].

Results have shown that although caregivers are willing to help their loved ones; at times at a personal cost, $\mathrm{AD}$ caregivers have a much higher chance of being clinically depressed than age-matched controls $[84,85]$. Thus, many psychosocial therapies have been explored to primarily help caregivers, which frequently lead to better care of patients. Mittelman explains that individualized counseling and involvement in caregiver support groups result in longlasting lower caregiver distress, even at followups at one and three years later [86]. Furthermore, lower distress and depressive symptoms were observed across caregivers for patients with varying dementia severity, living conditions, and after death of the patient [86].

It appears that enhanced social interactions may decrease the risk of $\mathrm{AD}$ and improve patients' $\mathrm{QOL}$, self-confidence, and possibly prognosis. Although it appears that socialization is important in supporting cognitive abilities in the normal elderly, further research is needed to clarify how and to what extent socialization benefits patients with $\mathrm{AD}$. 
TABLE 3: Summary of studies on the effect of socialization on incident dementia.

\begin{tabular}{|c|c|c|c|c|c|c|}
\hline Study & $\begin{array}{l}\text { Length and } \\
\text { frequency }\end{array}$ & Protocol & Sample & $\begin{array}{l}\text { MMSE } \\
\text { (baseline } \\
\text { mean) }\end{array}$ & Outcome measures & Major findings \\
\hline Wilson et al. [76] & $\begin{array}{l}4 \text { years; } \\
\text { annual check } \\
\text { up }\end{array}$ & $\begin{array}{l}\text { Longitudinal } \\
\text { clinicopathological } \\
\text { cohort study }\end{array}$ & $n=823$ & & $\begin{array}{l}\text { (i) Clinical diagnosis } \\
\text { of } \mathrm{AD} \\
\text { (ii) Change in } \\
\text { measures of global } \\
\text { cognition and specific } \\
\text { cognitive functions }\end{array}$ & $\begin{array}{l}\text { (i) Loneliness } \\
\text { associated with } \\
\text { cognitive decline and } \\
\text { development of AD }\end{array}$ \\
\hline Wang et al. [77] & $\begin{array}{l}\text { Data } \\
\text { collection ( } 9 \\
\text { years) }\end{array}$ & $\begin{array}{l}\text { Longitudinal } \\
\text { population-based } \\
\text { study }\end{array}$ & $n=776$ & 27.3 & $\begin{array}{l}\text { (i) Frequency of social } \\
\text { and leisure activities } \\
\text { engaged } 6.4 \text { years } \\
\text { before diagnosis } \\
\text { (ii) Baseline MMSE } \\
\text { (iii) MMSE of } \\
\text { incident dementia } \\
\text { cases }\end{array}$ & $\begin{array}{l}\text { (i) Socially and } \\
\text { mentally stimulating } \\
\text { activity may preserve } \\
\text { mental functioning in } \\
\text { the elderly, reducing } \\
\text { risk of dementia }\end{array}$ \\
\hline Friedland et al. [78] & & $\begin{array}{l}\text { Questionnaire data } \\
\text { collection }\end{array}$ & $\begin{array}{l}n_{\mathrm{AD}}=193 \\
n_{\mathrm{HC}}=358\end{array}$ & & $\begin{array}{l}\text { (i) Monthly } \\
\text { involvement in } \\
\text { possible } 26 \\
\text { nonoccupational } \\
\text { activities at early } \\
\text { adulthood and } \\
\text { middle adulthood }\end{array}$ & $\begin{array}{l}\text { (i) AD patients are } \\
\text { less active in midlife } \\
\text { than HC participants }\end{array}$ \\
\hline Bennet et al. [79] & 6-7 years & $\begin{array}{l}\text { Longitudinal, } \\
\text { epidemiological } \\
\text { clinicopathological } \\
\text { cohort study }\end{array}$ & $n=89$ & $\begin{array}{l}25.8 \text { (not } \\
\text { used in } \\
\text { analysis) }\end{array}$ & $\begin{array}{l}\text { (i) Annual clinical } \\
\text { evaluation } \\
\text { (ii) Brain autopsy at } \\
\text { death } \\
\text { (iii) Social network } \\
\text { size (number of } \\
\text { individuals seen at } \\
\text { least once/month) }\end{array}$ & $\begin{array}{l}\text { (i) Larger social } \\
\text { network sizes } \\
\text { observed in } \\
\text { participants with } \\
\text { higher level of } \\
\text { cognition }\end{array}$ \\
\hline Fratiglioni et al. [80] & 3 years & $\begin{array}{l}\text { Longitudinal } \\
\text { community-based } \\
\text { study }\end{array}$ & $n_{\mathrm{HC}}=1203$ & $>23$ & $\begin{array}{l}\text { (i) Social network at } \\
\text { baseline, clinical } \\
\text { evaluation at baseline } \\
\text { and } 3 \text { years }\end{array}$ & $\begin{array}{l}\text { (i) Limited social } \\
\text { network ties and } \\
\text { interaction increased } \\
\text { risk of developing } \\
\text { dementia }\end{array}$ \\
\hline
\end{tabular}

$n_{\mathrm{HC}}, n_{\mathrm{AD}}$ : number of participants in healthy control group and group diagnosed with AD. MMSE: Mini-Mental State Examination.

\section{Multimodal Therapy}

Given that physical exercise, intellectual stimulation, and socialization have individually shown to benefit AD patients, we summarize the results of multimodal interventions, combining at least two of the three activity types.

Coelho et al. [87] found that participants who engaged in an exercise program while simultaneously completing cognitive tasks had significantly higher scores $(P<0.001)$ than the control group on the Frontal Assessment Battery, which measures frontal lobe cognitive function. Furthermore, participants in the control group demonstrated decreased executive and visuospatial abilities through lower scores on a clock drawing test. The physical exercise program consisted of aerobic, flexibility and balance exercises, and resistance training. Cognitive tasks included generating words according to specific criteria (e.g., flowers, animals) or reacting to sensory stimuli such as verbal commands. These findings suggest that there is a place for physical exercise combined with intellectual stimulation in AD management.

Arkin [88] provides further support for the use of multimodal intervention through a study of $24 \mathrm{AD}$ patients engaged in exercise (aerobic and weight training), cognitive tasks (taking place before, during, and after exercise), and social activities. Compared to controls, the 4-year intervention group experienced no decline in several cognitive measures: MMSE, Clinical Dementia Rating Scale, verbal fluency, Boston Naming, and WAIS-R Comprehension. Burgener et al. [89] conducted a trial in which 24 early-AD patients received a multimodal intervention (exercise, cognitive behavioral therapy, and support group) and were compared to 19 patient control group who received attention-control educational programs. In addition to physical and behavioral outcome benefits, there was a significant difference in MMSE 
scores between the intervention and control groups, not present at baseline. As such, both studies suggest that multimodal intervention programs can help delay the cognitive decline characteristic of AD.

It is important to note, however, that evidence supporting multimodal intervention is not yet conclusive. A pilot study of $14 \mathrm{AD}$ patients by Maci et al. [90] found that participants engaged in a multimodal program of exercise (balance, gait, and coordination), cognitive stimulation, and socialization (talking/singing with other participants) led to reduced depression and improved anxiety and quality of life. However, there were no significant between-group differences in cognition as measured by the MMSE and Frontal Assessment Battery. It is possible that behavioral improvements may have been secondary to the very small sample size. Conflicting findings such as these indicate the need for further research in this area.

While the impact of multimodal interventions (and perhaps even each intervention independently) on reducing cognitive decline in $\mathrm{AD}$ remains unclear, it appears that patients may benefit in other ways from physical exercise, intellectual stimulation, and socialization. More research into the effects of multimodal therapies is required.

\section{Conclusions}

In summary, this paper highlights key research on the effectiveness of nonpharmacological treatment options, specifically exercise, intellectual stimulation, and socialization, on the progression of $\mathrm{AD}$. Based on our findings in the literature, all three intervention strategies may provide positive effects on cognition and overall wellbeing. More specifically, physical exercise appears to benefit various aspects of cognition in $\mathrm{AD}$ patients including stabilization of MMSE scores, and improved attention, memory and recognition, and ability to perform ADLs. It has also been demonstrated that regular exercise is helpful in reducing the risk of $\mathrm{AD}$ development and progression. Future studies should include a broader range of exercises to determine the most effective exercise regime for $\mathrm{AD}$ patients. Increased social interaction has been shown to benefit Alzheimer's patients by minimizing one's sense of loneliness, isolation, stress, and vascular factors that contribute to cognitive decline. It can also improve patients' sense of self-worth. However, limited studies exist on the benefits of socialization on cognition in the $\mathrm{AD}$ population. Studies focusing on these areas would help verify if a social component would provide more than simply behavioral benefits. In addition, intellectual stimulation may benefit $\mathrm{AD}$ patients by improving their cognition, emotional and social wellbeing as well as performance of ADLs. However, inconsistent results on the effectiveness of intellectual stimulation in delaying cognitive decline in $\mathrm{AD}$ patients demonstrate the need for further research.

It is necessary for future research to identify and address limitations found in the current literature. Patient recruitment can be a significant challenge in those with moderate-to-advanced $\mathrm{AD}$ due to the necessary comprehension levels for study completion. In addition, as dementia progresses, patients may become increasingly tired and frustrated, leading to higher attrition rates. Some of the studies do not provide adequate characterization of the enrolled population, rendering comparisons difficult. The ability to make between-study comparisons is further limited by the broad range of physical, cognitive, and social activities used in nonpharmacological therapies. Determining which nonpharmacological therapy is the most beneficial to the $\mathrm{AD}$ population is difficult due to the widespread and overlapping positive effects of each activity. As the goal of this paper was to provide a general overview of nonpharmacological interventions in $\mathrm{AD}$, we were limited in our ability to produce statistical analysis. Therefore, a meta-analysis is suggested in order to obtain quantitative results.

Based on the literature presented in this paper, patients experience less depression and improved quality of life, ability to perform ADLs, and social relationships. Most importantly, interventions that combine physical exercise and socialization with cognitive stimulation are often highly enjoyable for patients, leading to participants expressing their approval by saying: "This has been the only thing I have found that feels like I am doing something to help myself" [89]. Thus, the aforementioned nonpharmacological therapies are recommended in $\mathrm{AD}$ management.

\section{Authors' Contribution}

The first three authors contributed equally to this work.

\section{References}

[1] J. L. Cummings, “Alzheimer's disease," New England Journal of Medicine, vol. 351, no. 1, pp. 56-67, 2004.

[2] W. Thies and L. Bleiler, "Alzheimer's disease facts and figures," Alzheimer's and Dementia, vol. 7, no. 2, pp. 208-244, 2011.

[3] A. L. Fitzpatrick, L. H. Kuller, D. G. Ives et al., "Incidence and prevalence of dementia in the cardiovascular health study," Journal of the American Geriatrics Society, vol. 52, no. 2, pp. 195-204, 2004.

[4] R. Brookmeyer, S. Gray, and C. Kawas, "Projections of Alzheimer's disease in the United States and the public health impact of delaying disease onset," American Journal of Public Health, vol. 88, no. 9, pp. 1337-1342, 1998.

[5] R. M. Sousa, C. P. Ferri, D. Acosta et al., "Contribution of chronic diseases to disability in elderly people in countries with low and middle incomes: a 10/66 Dementia Research Group population-based survey," The Lancet, vol. 374, no. 9704, pp. 1821-1830, 2009.

[6] K. E. Powell, P. D. Thompson, C. J. Caspersen, and J. S. Kendrick, "Physical activity and the incidence of coronary heart disease," Annual Review of Public Health, vol. 8, pp. 253287, 1987.

[7] A. M. Kriska, S. N. Blair, and M. A. Pereira, "The potential role of physical activity in the prevention of non-insulindependent diabetes mellitus: the epidemiological evidence," Exercise and Sport Sciences Reviews, vol. 22, pp. 121-143, 1994.

[8] S. N. Blair and S. Brodney, "Effects of physical inactivity and obesity on morbidity and mortality: Current evidence and research issues," Medicine and Science in Sports and Exercise, vol. 31, no. 11, pp. S646-S662, 1999. 
[9] I. M. Lee, "Physical activity and cancer prevention—data from epidemiologic studies," Medicine and Science in Sports and Exercise, vol. 35, no. 11, pp. 1823-1827, 2003.

[10] D. Bonaiuti, B. Shea, R. Iovine et al., "Exercise for preventing and treating osteoporosis in postmenopausal women," Cochrane Database of Systematic Reviews, no. 3, Article ID CD000333, 2002.

[11] S. N. Blair, N. N. Goodyear, L. W. Gibbons, and K. H. Cooper, "Physical fitness and incidence of hypertension in healthy normotensive men and women," Journal of the American Medical Association, vol. 252, no. 4, pp. 487-490, 1984.

[12] A. D. Brown, C. A. McMorris, R. S. Longman et al., "Effects of cardiorespiratory fitness and cerebral blood flow on cognitive outcomes in older women," Neurobiology of Aging, vol. 31, no. 12, pp. 2047-2057, 2010.

[13] P. J. Smith, J. A. Blumenthal, B. M. Hoffman et al., "Aerobic exercise and neurocognitive performance: a metaanalytic review of randomized controlled trials," Psychosomatic Medicine, vol. 72, no. 3, pp. 239-252, 2010.

[14] K. I. Erickson and A. F. Kramer, "Aerobic exercise effects on cognitive and neural plasticity in older adults," British Journal of Sports Medicine, vol. 43, no. 1, pp. 22-24, 2009.

[15] L. J. Podewils, E. Guallar, L. H. Kuller et al., "Physical activity, APOE genotype, and dementia risk: findings from the Cardiovascular Health Cognition Study," American Journal of Epidemiology, vol. 161, no. 7, pp. 639-651, 2005.

[16] D. Laurin, R. Verreault, J. Lindsay, K. MacPherson, and K. Rockwood, "Physical activity and risk of cognitive impairment and dementia in elderly persons," Archives of Neurology, vol. 58 , no. 3, pp. 498-504, 2001.

[17] E. B. Larson, L. Wang, J. D. Bowen et al., "Exercise is associated with reduced risk for incident dementia among persons 65 years of age and older," Annals of Internal Medicine, vol. 144, no. 2, pp. 73-81, 2006.

[18] A. S. Buchman, P. A. Boyle, L. Yu, R. C. Shah, R. S. Wilson, and D. A. Bennett, "Total daily physical activity and the risk of AD and cognitive decline in older adults," Neurology, vol. 78, no. 17, pp. 1323-1329, 2012.

[19] N. T. Lautenschlager, K. L. Cox, L. Flicker et al., "Effect of physical activity on cognitive function in older adults at risk for Alzheimer disease: a randomized trial," Journal of the American Medical Association, vol. 300, no. 9, pp. 1027-1037, 2008.

[20] J. E. Ahlskog, Y. E. Geda, N. R. Graff-Radford, and R. C. Petersen, "Physical exercise as a preventive or diseasemodifying treatment of dementia and brain aging," Mayo Clinic Proceedings, vol. 86, no. 9, pp. 876-884, 2011.

[21] M. Weih, Ü. Degirmenci, S. Kreil, and J. Kornhuber, "Physical activity and alzheimer's disease: a meta-analysis of cohort studies," The Journal of Gerontopsychology and Geriatric Psychiatry, vol. 23, no. 1, pp. 17-20, 2010.

[22] L. Palleschi, F. Vetta, E. De Gennaro et al., "Effect of aerobic training on the cognitive performance of elderly patients with senile dementia of Alzheimer type," Archives of Gerontology and Geriatrics, vol. 22, no. 1, pp. 47-50, 1996.

[23] G. F. Lindenmuth and B. Moose, "Improving cognitive abilities of elderly Alzheimer's patients with intense exercise therapy," American Journal of Alzheimer's Care and Related Disorders and Research, vol. 5, no. 1, pp. 31-33, 1990.

[24] P. Heyn, B. C. Abreu, and K. J. Ottenbacher, "The effects of exercise training on elderly persons with cognitive impairment and dementia: a meta-analysis," Archives of Physical Medicine and Rehabilitation, vol. 85, no. 10, pp. 1694-1704, 2004.
[25] C. A. Alessi, E. Yoon, J. F. Schnelle, N. R. Al-Samanai, and P. A. Cruise, "A randomized trial of a combined physical activity and environmental intervention in nursing home residents: do sleep and agitation improve?" Journal of the American Geriatrics Society, vol. 47, no. 7, pp. 784-791, 1999.

[26] L. Teri, L. E. Gibbons, S. M. McCurry et al., "Exercise plus behavioral management in patients with Alzheimer disease: a randomized controlled trial," Journal of the American Medical Association, vol. 290, no. 15, pp. 2015-2022, 2003.

[27] G. Kemoun, M. Thibaud, N. Roumagne et al., "Effects of a physical training programme on cognitive function and walking efficiency in elderly persons with dementia," Dementia and Geriatric Cognitive Disorders, vol. 29, no. 2, pp. 109-114, 2010.

[28] D. K. Miu, S. L. Szeto, and Y. F. Mak, "A randomised controlled trial on the effect of exercise on physical, cognitive and affective function in dementia subjects," Asian Journal of Gerontology and Geriatrics, vol. 3, no. 1, pp. 8-16, 2008.

[29] K. E. Roach, R. M. Tappen, N. Kirk-Sanchez, C. L. Williams, and D. Loewenstein, "A randomized controlled trial of an activity specific exercise program for individuals with Alzheimer disease in long-term care settings," Journal of Geriatric Physical Therapy, vol. 34, no. 2, pp. 50-56, 2011.

[30] Y. Rolland, F. Pillard, A. Klapouszczak et al., "Exercise program for nursing home residents with Alzheimer's disease: a 1year randomized, controlled trial," Journal of the American Geriatrics Society, vol. 55, no. 2, pp. 158-165, 2007.

[31] M. Steinberg, J. M. Sheppard Leoutsakos, L. J. Podewills, and C. G. Lyketsos, "Evaluation of a home-based exercise program in the treatment of Alzheimer's disease: the Maximizing Independence in Dementia (MIND) study," International Journal of Geriatric Psychiatry, vol. 24, no. 7, pp. 680-685, 2009.

[32] M. Venturelli, R. Scarsini, and F. Schena, "Six-month walking program changes cognitive and ADL performance in patients with Alzheimer," American Journal of Alzheimer's Disease and other Dementias, vol. 26, no. 5, pp. 381-388, 2011.

[33] A. Vreugdenhil, J. Cannell, A. Davies, and G. Razay, "A community-based exercise programme to improve functional ability in people with Alzheimer's disease: a randomized controlled trial," Scandinavian Journal of Caring Sciences, vol. 26, no. 1, pp. 12-19, 2012.

[34] L. Yágüez, K. N. Shaw, R. Morris, and D. Matthews, "The effects on cognitive functions of a movement-based intervention in patients with Alzheimer's type dementia: a pilot study," International Journal of Geriatric Psychiatry, vol. 26, no. 2, pp. 173-181, 2011.

[35] R. C. Cassilhas, V. A. R. Viana, V. Grassmann et al., "The impact of resistance exercise on the cognitive function of the elderly," Medicine and Science in Sports and Exercise, vol. 39, no. 8, pp. 1401-1407, 2007.

[36] T. Liu-Ambrose, M. G. Donaldson, Y. Ahamed et al., "Otago home-based strength and balance retraining improves executive functioning in older fallers: a randomized controlled trial," Journal of the American Geriatrics Society, vol. 56, no. 10, pp. 1821-1830, 2008.

[37] B. S. Oken, D. Zajdel, S. Kishiyama et al., "Randomized, controlled, six-month trial of yoga in healthy seniors: effects on cognition and quality of life," Alternative Therapies in Health and Medicine, vol. 12, no. 1, pp. 40-47, 2006.

[38] S. J. Colcombe, K. I. Erickson, P. E. Scalf et al., "Aerobic exercise training increases brain volume in aging humans," Journals of Gerontology, vol. 61, no. 11, pp. 1166-1170, 2006. 
[39] M. W. Voss, R. S. Prakash, K. I. Erickson et al., "Plasticity of brain networks in a randomized intervention trial of exercise training in older adults," Froniers in Aging Neuroscience, vol. 2, p. 32, 2010.

[40] J. M. Burns, B. B. Cronk, H. S. Anderson et al., "Cardiorespiratory fitness and brain atrophy in early Alzheimer disease," Neurology, vol. 71, no. 3, pp. 210-216, 2008.

[41] R. A. Honea, G. P. Thomas, A. Harsha et al., "Cardiorespiratory fitness and preserved medial temporal lobe volume in alzheimer disease," Alzheimer Disease and Associated Disorders, vol. 23, no. 3, pp. 188-197, 2009.

[42] R. S. Wilson, D. A. Bennett, J. L. Bienias et al., "Cognitive activity and incident $\mathrm{AD}$ in a population-based sample of older persons," Neurology, vol. 59, no. 12, pp. 1910-1914, 2002.

[43] M. Valenzuela and P. Sachdev, "Can cognitive exercise prevent the onset of dementia? systematic review of randomized clinical trials with longitudinal follow-up," American Journal of Geriatric Psychiatry, vol. 17, no. 3, pp. 179-187, 2009.

[44] T. F. Hughes, C. C. H. Chang, J. Vander Bilt, and M. Ganguli, "Engagement in reading and hobbies and risk of incident dementia: the MoVIES project," American Journal of Alzheimer's Disease and other Dementias, vol. 25, no. 5, pp. 432-438, 2010.

[45] Y. Stern, "What is cognitive reserve? Theory and research application of the reserve concept," Journal of the International Neuropsychological Society, vol. 8, no. 3, pp. 448-460, 2002.

[46] N. Scarmeas and Y. Stern, "Cognitive reserve and lifestyle," Journal of Clinical and Experimental Neuropsychology, vol. 25, no. 5, pp. 625-633, 2003.

[47] N. Scarmeas and Y. Stern, "Cognitive reserve: implications for diagnosis and prevention of Alzheimer's disease," Current Neurology and Neuroscience Reports, vol. 4, no. 5, pp. 374-380, 2004.

[48] L. Mowszowski, J. Batchelor, and S. L. Naismith, "Early intervention for cognitive decline: can cognitive training be used as a selective prevention technique?" International Psychogeriatrics, vol. 22, no. 4, pp. 537-548, 2010.

[49] Y. Stern, S. Albert, M. X. Tang, and W. Y. Tsai, "Rate of memory decline in $\mathrm{AD}$ is related to education and occupation: cognitive reserve?" Neurology, vol. 53, no. 9, pp. 1942-1947, 1999.

[50] E. P. Helzner, N. Scarmeas, S. Cosentino, F. Portet, and Y. Stern, "Leisure activity and cognitive decline in incident Alzheimer disease," Archives of Neurology, vol. 64, no. 12, pp. 1749-1754, 2007.

[51] K. A. Treiber, M. C. Carlson, C. Corcoran et al., "Cognitive stimulation and cognitive and functional decline in Alzheimer's disease: the Cache County Dementia Progression Study," The Journals of Gerontology, Series B, vol. 66, no. 4, pp. 416-425, 2011.

[52] C. Ballard, Z. Khan, H. Clack, and A. Corbett, "Nonpharmacological treatment of Alzheimer disease," Canadian Journal of Psychiatry, vol. 56, no. 10, pp. 589-595, 2011.

[53] F. Yu F, K. M. Rose, S. C. Burgener et al., "Cognitive training for early-stage Alzheimer's disease and dementia," Journal of Gerontological Nursing, vol. 35, no. 3, pp. 23-29, 2009.

[54] A. F. Kurz, S. Leucht, and N. T. Lautenschlager, "The clinical significance of cognition-focused interventions for cognitively impaired older adults: a systematic review of randomized controlled trials," International Psychogeriatrics, vol. 23, no. 9, pp. 1364-1375, 2011.

[55] D. I. Sitzer, E. W. Twamley, and D. V. Jeste, "Cognitive training in Alzheimer's disease: a meta-analysis of the literature," Acta Psychiatrica Scandinavica, vol. 114, no. 2, pp. 75-90, 2006.
[56] B. Woods, E. Aguirre, A. E. Spector, and M. Orrell, "Cognitive stimulation to improve cognitive functioning in people with dementia," Cochrane Database of Systematic Reviews, no. 2, Article ID CD005562, 2012.

[57] A. Spector, L. Thorgrimsen, B. Woods et al., "Efficacy of an evidence-based cognitive stimulation therapy programme for people with dementia: randomised controlled trial," British Journal of Psychiatry, vol. 183, pp. 248-254, 2003.

[58] S. B. Chapman, M. F. Weiner, A. Rackley, L. S. Hynan, and J. Zientz, "Effects of cognitive-communication stimulation for Alzheimer's disease patients treated with donepezil," Journal of Speech, Language, and Hearing Research, vol. 47, no. 5, pp. 1149-1163, 2004.

[59] V. C. Buschert, U. Friese, S. J. Teipel et al., "Effects of a newly developed cognitive intervention in amnestic mild cognitive impairment and mild Alzheimer's disease: a pilot study," Journal of Alzheimer's Disease, vol. 25, no. 4, pp. 679-694, 2011.

[60] G. Onder, O. Zanetti, E. Giacobini et al., "Reality orientation therapy combined with cholinesterase inhibitors in Alzheimer's disease: randomised controlled trial," British Journal of Psychiatry, vol. 187, pp. 450-455, 2005.

[61] A. Spector, S. Davies, B. Woods, and M. Orrell, "Reality orientation for dementia: a systematic review of the evidence of effectiveness from randomized controlled trials," Gerontologist, vol. 40, no. 2, pp. 206-212, 2000.

[62] L. Clare and B. Woods, "Cognitive rehabilitation and cognitive training for early-stage Alzheimer's disease and vascular dementia," Cochrane Database of Systematic Reviews, no. 4, Article ID CD003260, 2008.

[63] L. Clare, D. E. J. Linden, R. T. Woods et al., "Goal-oriented cognitive rehabilitation for people with early-stage alzheimer disease: a single-blind randomized controlled trial of clinical efficacy," American Journal of Geriatric Psychiatry, vol. 18, no. 10, pp. 928-939, 2010.

[64] D. A. Loewenstein, A. Acevedo, S. J. Czaja, and R. Duara, "Cognitive rehabilitation of mildly impaired Alzheimer disease patients on cholinesterase inhibitors," American Journal of Geriatric Psychiatry, vol. 12, no. 4, pp. 395-402, 2004.

[65] R. N. Davis, P. J. Massman, and R. S. Doody, "Cognitive intervention in Alzheimer disease: a randomized placebocontrolled study," Alzheimer Disease and Associated Disorders, vol. 15, no. 1, pp. 1-9, 2001.

[66] M. P. Quayhagen, M. Quayhagen, R. R. Corbeil et al., "Coping with dementia: evaluation of four nonpharmacologic interventions," International Psychogeriatrics, vol. 12, no. 2, pp. 249-265, 2000.

[67] D. C. Koltai, K. A. Welsh-Bohmer, and D. E. Schmechel, "Influence of anosognosia on treatment outcome among dementia patients," Neuropsychological Rehabilitation, vol. 11, no. 3-4, pp. 455-475, 2001.

[68] G. W. Small, P. V. Rabins, P. P. Barry et al., "Diagnosis and treatment of Alzheimer disease and related disorders: consensus statement of the American Association for Geriatric Psychiatry, the Alzheimer's Association, and the American Geriatrics Society," Journal of the American Medical Association, vol. 278, no. 16, pp. 1363-1371, 1997.

[69] L. J. Thal, "Prevention of Alzheimer disease," Alzheimer Disease and Associated Disorders, vol. 20, no. 2, pp. S97-S99, 2006.

[70] L. P. De Vreese, M. Neri, M. Fioravanti, L. Belloi, and O. Zanetti, "Memory rehabilitation in Alzheimer's disease: a review of progress," International Journal of Geriatric Psychiatry, vol. 16, no. 8, pp. 794-809, 2001. 
[71] D. A. Cahn-Weiner, P. F. Malloy, G. W. Rebok, and B. R. Ott, "Results of a randomized placebo-controlled study of memory training for mildly impaired Alzheimer's disease patients," Applied Neuropsychology, vol. 10, no. 4, pp. 215-223, 2003.

[72] E. Farina, F. Mantovani, R. Fioravanti et al., "Evaluating two group programmes of cognitive training in mild-to-moderate $\mathrm{AD}$ : is there any difference between a "global" stimulation and a "cognitive-specific" one?" Aging and Mental Health, vol. 10, no. 3, pp. 211-218, 2006.

[73] H. MacRae, "Self and other: the importance of social interaction and social relationships in shaping the experience of early-stage Alzheimer's disease," Journal of Aging Studies, vol. 25, pp. 445-456, 2011.

[74] L. Fratiglioni, S. Paillard-Borg, and B. Winblad, "An active and socially integrated lifestyle in late life might protect against dementia," The Lancet Neurology, vol. 3, no. 6, pp. 343-353, 2004.

[75] K. H. Pitkala, P. Routasalo, H. Kautiainen, H. Sintonen, and R. S. Tilvis, "Effects of socially stimulating group intervention on lonely, older people's cognition: a randomized, controlled trial," American Journal of Geriatric Psychiatry, vol. 19, no. 7, pp. 654-663, 2011.

[76] R. S. Wilson, K. R. Krueger, S. E. Arnold et al., "Loneliness and risk of Alzheimer disease," Archives of General Psychiatry, vol. 64, no. 2, pp. 234-240, 2007.

[77] H. X. Wang, A. Karp, B. Winblad, and L. Fratiglioni, "Late-life engagement in social and leisure activities is associated with a decreased risk of dementia: a longitudinal study from the Kungsholmen Project," American Journal of Epidemiology, vol. 155, no. 12, pp. 1081-1087, 2002.

[78] R. P. Friedland, T. Fritsch, K. A. Smyth et al., "Patients with Alzheimer's disease have reduced activities in midlife compared with healthy control-group members," Proceedings of the National Academy of Sciences of the United States of America, vol. 98, no. 6, pp. 3440-3445, 2001.

[79] D. A. Bennett, J. A. Schneider, Y. Tang, S. E. Arnold, and R. S. Wilson, "The effect of social networks on the relation between Alzheimer's disease pathology and level of cognitive function in old people: a longitudinal cohort study," The Lancet Neurology, vol. 5, no. 5, pp. 406-412, 2006.

[80] L. Fratiglioni, H. X. Wang, K. Ericsson, M. Maytan, and B. Winblad, "Influence of social network on occurrence of dementia: a community-based longitudinal study," The Lancet, vol. 355, no. 9212, pp. 1315-1319, 2000.

[81] H. H. Keller, L. S. Martin, S. Dupuis, R. Genoe, H. G. Edward, and C. Cassolato, "Mealtimes and being connected in the community-based dementia context," Dementia, vol. 9, no. 2, pp. 191-213, 2010.

[82] R. G. Logsdon, S. M. McCurry, and L. Teri, "Evidence-based interventions to improve quality of life for individuals with dementia," Alzheimer's Care Today, vol. 8, no. 4, pp. 309-318, 2007.

[83] R. G. Logsdon, K. C. Pike, S. M. McCurry et al., "Early-stage memory loss support groups: outcomes from a randomized controlled clinical trial," Journals of Gerontology, vol. 65, no. 6, pp. 691-697, 2010.

[84] M. S. Mittelman, S. H. Ferris, E. Shulman et al., "A comprehensive support program: effect on depression in spousecaregivers of AD patients," Gerontologist, vol. 35, no. 6, pp. 792-802, 1995.

[85] M. S. Mittelman, C. Epstein, and A. Pierzchala, Counselling the Alzheimer's Caregiver: A Resource for Health Care Professionals, American Medical Association, Chicago, Ill, USA, 2001.
[86] M. S. Mittelman, D. L. Roth, D. W. Coon, and W. E. Haley, "Sustained benefit of supportive intervention for depressive symptoms in caregivers of patients with Alzheimer's disease," American Journal of Psychiatry, vol. 161, no. 5, pp. 850-856, 2004.

[87] F. G. M. Coelho, L. P. Andrade, R. V. Pedroso et al., "Multimodal exercise intervention improves frontal cognitive functions and gait in Alzheimer's disease: a controlled trial," Geriatriatrics and Gerontolology International. In press.

[88] S. Arkin, "Language-enriched exercise plus socialization slows cognitive decline in Alzheimer's disease," American Journal of Alzheimer's Disease and other Dementias, vol. 22, no. 1, pp. 6277, 2007.

[89] S. C. Burgener, Y. Yang, R. Gilbert, and S. Marsh-Yant, "The effects of a multimodal intervention on outcomes of persons with early-stage dementia," American Journal of Alzheimer's Disease and other Dementias, vol. 23, no. 4, pp. 382-394, 2008.

[90] T. Maci, F. Le Pira, G. Quattrocch, S. Di Nuovo, V. Perciavalle, and M. Zappia, "Physical and cognitive stimulation in Alzheimer disease. The GAIA Project: a pilot study," American Journal of Alzheimers Disease and other Dementias, vol. 27, no. 2, pp. 107-113, 2012. 


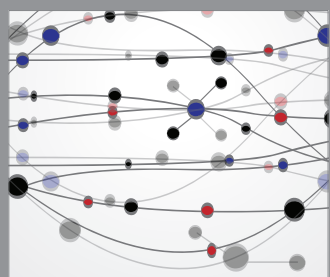

The Scientific World Journal
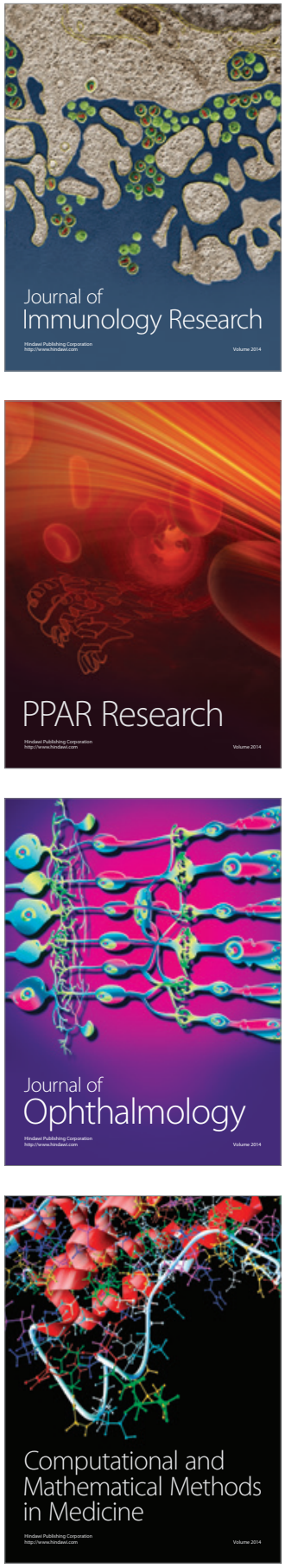

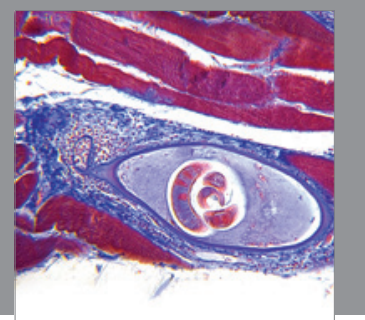

Gastroenterology

Research and Practice
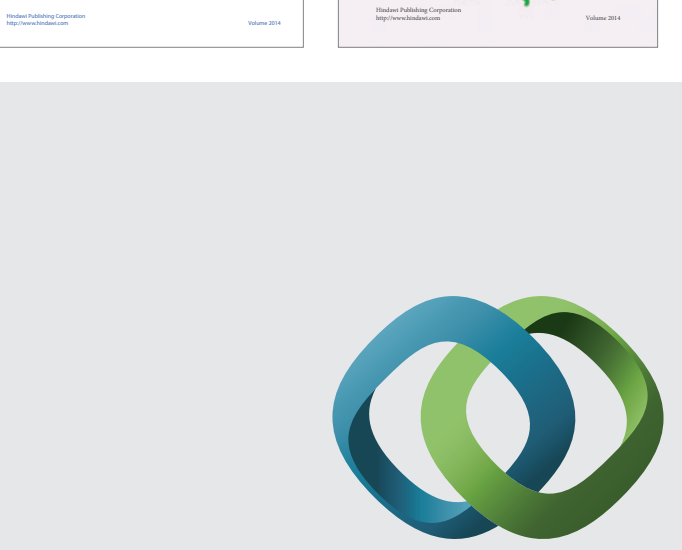

\section{Hindawi}

Submit your manuscripts at

http://www.hindawi.com
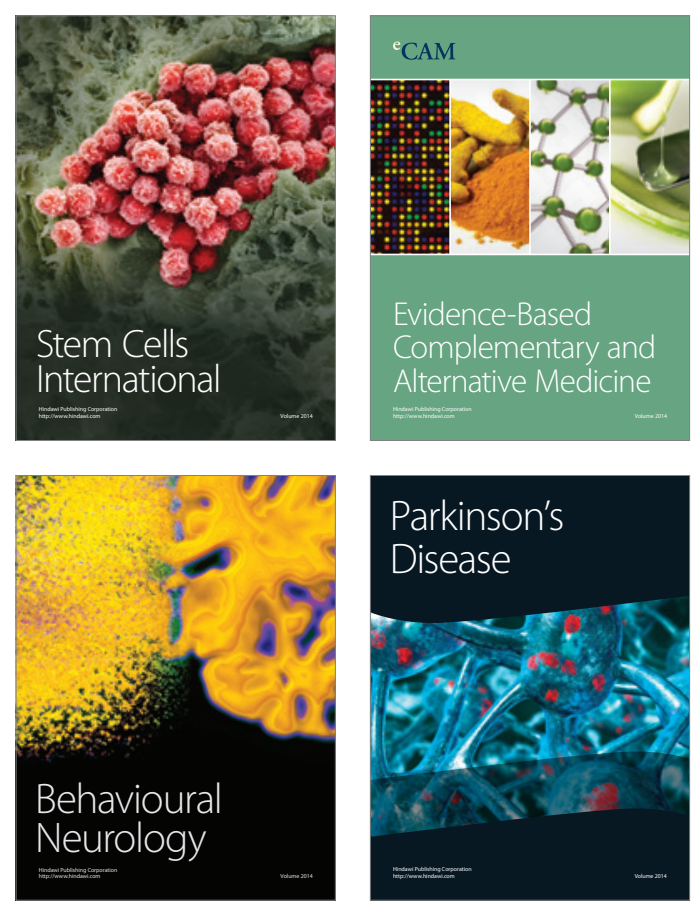

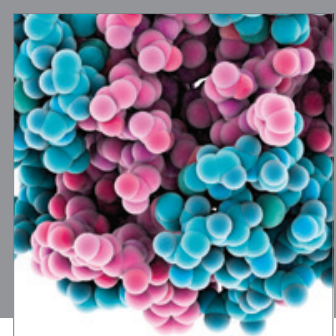

Journal of
Diabetes Research

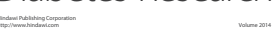

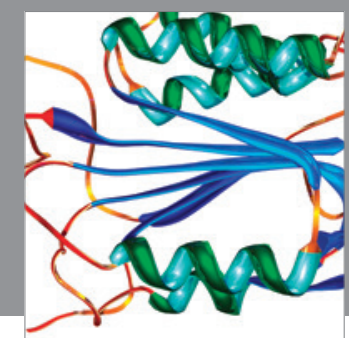

Disease Markers
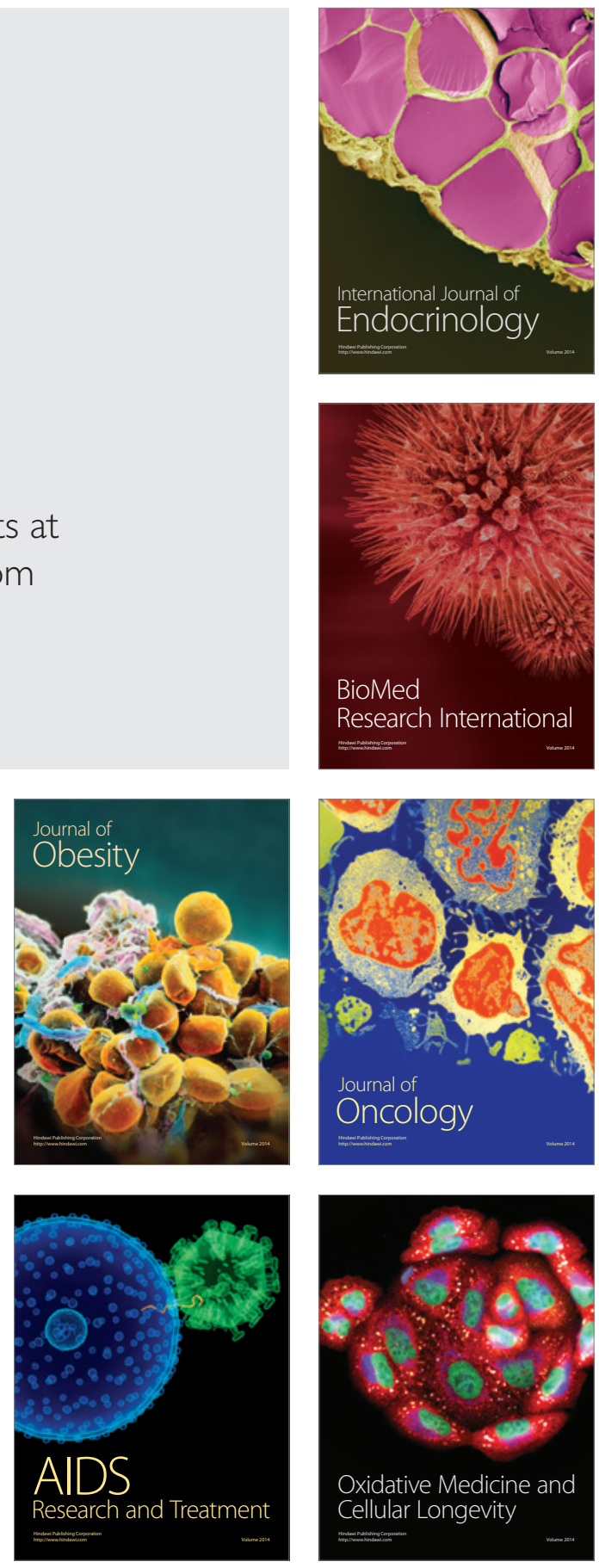